\title{
KNOWLEDGE OF PHARMACOGENETICS AMONG HEALTHCARE PROFESSIONALS AND FACULTY MEMBERS OF HEALTH TRAIN- ING INSTITUTIONS IN GHANA
}

\author{
W. KUDZI ${ }^{1}$, B. S. ADDY ${ }^{2}$ and B. DZUDZOR ${ }^{3}$ \\ ${ }^{1}$ Centre for Tropical Clinical Pharmacology and Therapeutics, School of Medicine and Dentistry, P. O. \\ GP 4236, Accra, Ghana ${ }^{2}$ Department of Pharmaceutical Science, School of Applied Sciences, Central \\ University College, P. O. Box 2305, Tema. Ghana ${ }^{3}$ Department of Medical Biochemistry, School of Bio- \\ medical and Allied Health Sciences, P.O. Box GT 143, Accra, Ghana
}

DOI: http://dx.doi.org/10.4314/gmj.v49i1.9

Corresponding Author: Dr William Kudzi

E-mail:wkudzi@yahoo.com

Conflict of interest: None Declared

\section{SUMMARY}

Background: Pharmacogenetics has a potential for optimizing drug response and identifying risk of toxicity for patients. Pharmacogenetics knowledge of healthcare professionals and the unmet need for pharmacogenetics education in health training institutions are some of the challenges of integrating pharmacogenetics into routine medical practice.

Aim: To assess pharmacogenetics knowledge among healthcare professionals and faculty members of health training institutions in Ghana.

Method: Semi-structured questionnaires were used to interview healthcare professionals from selected public and private hospitals. Faculty members from health training institutions were also interviewed. Results: The respondents were Medical doctors 42 (46.7\%), Pharmacists $29(32.2 \%)$ and Nurses 19 $(21.1 \%)$. Healthcare professionals rated their knowledge of Pharmacogenetics as Excellent 5 (5.6\%), Very Good 10 (11.2\%), Good 53 (60\%) and Poor 19 (21.4\%). Thirty-two faculty members from health training institutions were also interviewed. Faculty members rated their knowledge of pharmacogenetics as Excellent $2(6.3 \%)$, Very Good 3 (9.4\%), Good 9 (28.1\%), Fair $12(37.5 \%)$ and Poor 6 $(18.8 \%)$. Thirty seven percent (12) of these faculty members said pharmacogenetics was not part of their institutions' curriculum, $7(22 \%)$ did not know if pharmacogenetics was part of their curriculum and only $13(40.6 \%)$ said it was part of their curriculum. Conclusion: Few healthcare professionals and faculty members of training institutions are aware of the discipline of pharmacogenetics. There is the need for continuous professional education on pharmacogenetics and development of competency standards for all healthcare professionals in Ghana.
Keywords: Pharmacogenetics; Faculty, Curriculum, Education, Ghanaian

\section{INTRODUCTION}

There has been considerable scientific, corporate and policy interest in the more effective use of genetics in both drug development and delivery in the world. ${ }^{1}$ Available literature has documented variations in drug response among individuals leading to differences in the extent of adverse drug reactions as well as efficacy of drug treatment. ${ }^{2}$

The genetic make-up of the individual, in addition to both the physiological and environmental factors, have had a profound impact on individual's response to medications. Pharmacogenetics has been defined as the effect of genetic variation on drug response while Pharmacogenomics encompasses all genes in the genome that may determine drug response. ${ }^{3}$ Pharmacogenetics and Pharmacogenomics is being used interchangeably and is a new field which has potentially made it possible for the identification of individuals in whom a particular treatment will be effective or select those individuals who will have an increased chance of life threatening adverse reaction to a particular medication. ${ }^{4}$

Although pharmacogenetics testing is currently available only to a small number of patients, it is likely to influence clinical practice to a larger extent in the near future. ${ }^{5}$ Pharmacogenetics will serve to improve individual country's "ability to respond to local disease threats" and to "make better policy decisions regarding the most optimal interventions within their own health care delivery systems". 6 
The Food and Drug Administration of the United States of America (US-FDA) requires inclusion of pharmacogenetics information in over 100 drug labels, which is approximately $10 \%$ of all drug labels up to 2005. ${ }^{7}$ It is therefore important that all healthcare professionals (Doctors, Pharmacist, Physician Assistants and Nurses) in all areas where pharmacogenetics testing or information will be available are familiar with the knowledge to be able to interpret and sufficiently explain and incorporate it into the management of patients.

Information on pharmacogenetics research within indigenous African populations are scarce. ${ }^{8}$ Ghana is one of the few countries in Africa in which substantial genotype information is being accumulated, at least at the population level. ${ }^{2}$ Integrating this pharmacogenetic information into both public health decision-making and clinical practice still remains a goal all nations are aspiring to achieve.

Recognizing the significant anticipated opportunities and challenges that pharmacogenetics will bring to healthcare was the catalyst for an Academic Affairs Committee of the American Association of Colleges of Pharmacy (AACP) report in 2002. ${ }^{9}$ The American College of Physicians (ACP) in 2005 also acknowledged that it was increasingly important for physicians to be knowledgeable about genetic testing and counseling. In 2006, the American Nurses Association (ANA) established genetic competencies for nurses and recommended its use in nursing education. ${ }^{10}$ The National Coalition for Health Professional Education in Genetics (NCHPEG) then established core competencies expected of all healthcare professionals with associations representing individual specialties also following suit. ${ }^{11}$

It is therefore clear that inadequate education at undergraduate and postgraduate levels will be a hindrance to the wide spread introduction of pharmacogenetics into patient management. A report published in 2005 shows that $40 \%$ of pharmacy schools surveyed in the US did not have any instruction of Pharmacogenetics in their curriculum. ${ }^{12}$ In a second report, Pharmacogenetics was not taught in over $20 \%$ of the 41 responding US Pharmacy Schools. ${ }^{13}$ The academic members of the focus group of the 2008 American Association of Pharmaceutical Scientist therefore expressed concern about the need for pharmacogenetics teaching which have not been met and recommended that pharmacogenetics should be thought in Pharmacy schools.
The International Society of Pharmacogenetics published a number of recommendations in 2005 to increase Pharmacogenetics knowledge. This included the teaching of pharmacogenetics in undergraduate medical school. ${ }^{14}$

A study among 34 medical schools in the UK after the recommendation of International Society of Pharmacogenetics on teaching of Pharmacogenetics in undergraduate schools, showed that $19(56 \%)$ of these schools responded to the questionnaires. A total of $84 \%$ (16 out of 19) of schools that responded provided Pharmacogenetics teaching. ${ }^{15}$ A recent study in the US also showed that $92 \%$ (69 out of 75) colleges now include Pharmacogenetics in their Pharm D curriculum as compared to $50 \%$ (16 out of 32$)$ in $2005 .{ }^{16}$

Despite the outstanding amount of evidence promoting pharmacogenetics education and practice in some developed countries, most countries in the developing world of which Ghana is an example seem to be lagging behind in pharmacogenetics education in their universities.

The first objective of this survey is to assess the extent and depth of knowledge, perception and education of healthcare professionals in the area of pharmacogenetics in Ghana. The second objective is to determine the knowledge of pharmacogenetics among faculty members of healthcare training institutions in Ghana.

\section{METHODS}

This preliminary descriptive study was conducted in seven health institutions in the Greater Accra region and four academic institutions between March and June 2013 using Semi-structured questionnaires. The study was approved by Central University College Protocol Review Committee and consent was obtained from the respondents with assurance of anonymity of their responses before questionnaires were administered. The first part of the study involved respondents from a teaching hospital (Korle bu Teaching Hospital), a regional hospital (Ridge Hospital), an urban hospital (Tema General Hospital) and 4 other private clinics within the Accra/Tema metropolitan area. These seven health institutions were conveniently selected for the study as a fair representation of clinical practice in the region. The first set of 100 pretested questionnaires was administered to a convenient sample of healthcare professionals mainly doctors, pharmacists and nurses practicing in these health institutions.

A second set of 40 questionnaires was used to interview faculty members of health training institutions known to be associated with programs where genetics, biochemistry and pharmacology content were covered. 
These faculty members from the following health training institutions in Ghana were purposefully selected and approached for the study. The training institutions were the School of Medicine and Dentistry Korle-bu (University of Ghana); School of Pharmacy (University of Ghana); School of Medicine of Medical Sciences at Kwame Nkrumah University of Science and Technology (KNUST) Kumasi; School of Pharmacy (KNUST); and the School of Applied Sciences at Central University College (CUC) training Pharmacist and Physician Assistants. The questions used in this study were modeled on findings from previous literature regarding the incorporation of pharmacogenetics into clinical practice and a previous study by Latif and Mckay. ${ }^{13}$

\section{Statistical Analysis}

All data were entered into Statistical Package for Social Science (ver.17.0; SPSS, Chicago, IL) and imported into Stata $^{\mathrm{TM}}$ version 10 (StataCorp, College Station, Texas, United States) for statistical analyses. Data were summarized as frequencies and proportions.

\section{RESULTS}

Ninety of the $100(90 \%)$ healthcare professionals contacted completed and returned the questionnaires. Fortytwo $(46.7 \%)$ of these healthcare professionals were doctors, $29(32.2 \%)$ were pharmacists and 19 (21.1\%) were nurses practicing at selected hospitals and clinics within the Accra/Tema metropolitan area. Of these 90 respondents, $49(54 \%)$ were male and $41(46 \%)$ were female. Thirty four $(38 \%)$ of these responding professionals, had below 5 years of practice experience, 34 (38\%) had 5 years to 10 years practice experience and 22 (24\%) had been practicing for over 10 years. Majority of the healthcare professionals have heard the word pharmacogenetics from varied sources (Table 1).

Table 1 Source of pharmacogenetics information

\begin{tabular}{|l|l|l|l|l|l|l|l|}
\hline & $\begin{array}{l}\text { Not heard } \\
\mathrm{n}(\%)\end{array}$ & $\begin{array}{l}\text { Colleagues } \\
\mathrm{n}(\%)\end{array}$ & $\begin{array}{l}\text { Internet } \\
\mathrm{n}(\%)\end{array}$ & $\begin{array}{l}\text { Journal } \\
\mathrm{n}(\%)\end{array}$ & $\begin{array}{l}\text { Media } \\
\mathrm{n}(\%)\end{array}$ & $\begin{array}{l}\text { School } \\
\mathrm{n}(\%)\end{array}$ & $\begin{array}{l}\text { Seminar } \\
\mathrm{n}(\%)\end{array}$ \\
\hline Medical doctor & $0(0)$ & $16(38.1)$ & $12(28.6)$ & $1(2.4)$ & $1(2.4)$ & $12(28.6)$ & $0(0)$ \\
\hline Pharmacist & $1(3.5)$ & $6(20.7)$ & $12(41.4)$ & $0(0)$ & $3(10.3)$ & $7(24.1)$ & $0(0)$ \\
\hline Medical Nurse & $3(15.8)$ & $9(47.4)$ & $3(15.8)$ & $0(0)$ & $2(10.5)$ & $1(5.3)$ & $1(5.3)$ \\
\hline
\end{tabular}

Table 2 Rating of knowledge of pharmacogenetics

\begin{tabular}{|l|l|l|l|l|l|}
\hline & $\begin{array}{l}\text { Excellent } \\
\text { n (\%) }\end{array}$ & $\begin{array}{l}\text { Very Good } \\
\text { n (\%) }\end{array}$ & $\begin{array}{l}\text { Good } \\
\text { n (\%) }\end{array}$ & $\begin{array}{l}\text { Poor } \\
\text { n (\%) }\end{array}$ & $\begin{array}{l}\text { Very Poor } \\
\text { n (\%) }\end{array}$ \\
\hline Medical doctor & $1(2.4)$ & $5(11.9)$ & $32(76.2)$ & $4(9.5)$ & $0(0)$ \\
\hline Pharmacist* & $0(0)$ & $5(17.9)$ & $11(39.3)$ & $9(32.1)$ & $3(10.7)$ \\
\hline Nurse & $0(0)$ & $0(0)$ & $10(52.6)$ & $6(31.6)$ & $3(15.8)$ \\
\hline
\end{tabular}

* No response from 1 pharmacist

Table 2 shows the respondents' rating of their knowledge of pharmacogenetics as excellent, very good, good, poor, or very poor. All the respondents except one pharmacist answered this question.

All the doctors and pharmacists interviewed taught pharmacogenetics was relevant to their individual professions especially in the areas of diagnosis and treatment. Nine $(47.4 \%)$ of nurses however, do not think pharmacogenetics was relevant to their profession and two of these nurses do not think pharmacogenetics should be part diagnosis and treatment. All respondents, except one doctor and one pharmacist, said pharmacogenetics should be part of their continuous professional development (Table 3).
Table 3 Relevance of knowledge of pharmacogenetics Is pharmacogenetics relevant to your profession?

\begin{tabular}{|c|c|c|}
\hline & $\begin{array}{l}\text { No } \\
\text { n }(\%)\end{array}$ & $\begin{array}{l}\text { Yes } \\
\text { n }(\%)\end{array}$ \\
\hline Medical doctor & $0(0)$ & $42(100)$ \\
\hline Pharmacist & $0(0)$ & $29(100)$ \\
\hline Nurse & $9(47.4)$ & $10(52.6)$ \\
\hline \multicolumn{3}{|c|}{$\begin{array}{l}\text { Should pharmacogenetics be part of diagnosis } \\
\text { and treatment? }\end{array}$} \\
\hline Medical doctor & $0(0)$ & $42(100)$ \\
\hline Pharmacist & $0(0)$ & $29(100)$ \\
\hline Nurse & $2(10.5)$ & $17(89.5)$ \\
\hline \multicolumn{3}{|c|}{$\begin{array}{l}\text { Should pharmacogenetics information be in- } \\
\text { cluded in your continuing professional devel- } \\
\text { opment training? }\end{array}$} \\
\hline Medical doctor & $1(2.4)$ & $41(97.6)$ \\
\hline Pharmacist & $0(0)$ & $29(100)$ \\
\hline Nurse & $1(5.3)$ & $18(94.7)$ \\
\hline
\end{tabular}


Table 4 provides a summary of the opinions of health professionals surveyed. Nine $(21.4 \%)$ doctors, 10 (34.5) pharmacist and 10 (52.6) nurses were not sure if pharmacogenetic testing will help decrease the number of Adverse Drug Reactions (ADRs).

Table 4 Summary of knowledge of pharmacogenetics to diagnosis and treatment

\begin{tabular}{|l|l|l|l|l|}
\hline \multicolumn{1}{|c|}{ Item } & $\begin{array}{c}\text { Not im- } \\
\text { portant } \\
\mathbf{n}(\mathbf{\%})\end{array}$ & $\begin{array}{c}\text { Not } \\
\text { sure n } \\
\mathbf{( \% )}\end{array}$ & $\begin{array}{c}\text { Important } \\
\mathbf{n}(\mathbf{\%})\end{array}$ & $\begin{array}{c}\text { Very } \\
\text { Important } \\
\mathbf{n}(\mathbf{\%})\end{array}$ \\
\hline $\begin{array}{l}\text { How important is phar- } \\
\text { macogenetics for identifi- } \\
\text { cation of drug targets }\end{array}$ & $0(0)$ & $6(18.8)$ & $10(31.23)$ & $16(50)$ \\
\hline $\begin{array}{l}\text { How important is phar- } \\
\text { macogenetics for reducing } \\
\text { cost of treatment }\end{array}$ & $2(6.3)$ & $7(21.9)$ & $11(34.4)$ & $12(37.5)$ \\
\hline $\begin{array}{l}\text { How important is phar- } \\
\text { macogenetics for under- } \\
\text { standing drug action }\end{array}$ & $1(3.1)$ & $4(12.5)$ & $9(28.1)$ & $18(56.3)$ \\
\hline $\begin{array}{l}\text { How important is phar- } \\
\text { macogenetics for reducing } \\
\text { ADRs }\end{array}$ & $0(0)$ & $4(12.5)$ & $8(25)$ & $20(62.5)$ \\
\hline $\begin{array}{l}\text { How important is phar- } \\
\text { macogenetics for improv- } \\
\text { ing efficacy }\end{array}$ & $0(0)$ & $8(25)$ & $5(15.6)$ & $19(59.4)$ \\
\hline
\end{tabular}

The second objective of this survey was to assess the knowledge of pharmacogenetics among faculty members of selected Health training institutions. Thirty-two $(80 \%)$ out of the 40 questionnaires administered to faculty members of Health Training Institutions were completed and returned. Eight (25\%) these faculty members train only medical doctors, 18 (56.2\%) train only pharmacists and $6(18.8 \%)$ train both pharmacists and medical doctors.

Fifteen 17 (53.1\%) respondents indicated their field of expertise as being related to pharmacology or biology with the $15(46.9 \%)$ indicating their field of expertise as non-Pharmacology or Biology.

Nineteen $(59.4 \%)$ out of the 32 respondents have heard of pharmacogenetics which correlates with the number of respondents that said their field of expertise is relat- ed to pharmacology. The respondents rated their knowledge of pharmacogenetics as either excellent $(2$, $6.3 \%)$, very good $(3,9.4 \%)$, good $(9,28.1 \%)$, poor $(12$, $37.5 \%)$, and very poor $(6,18.8 \%)$.

Faculty members believe that pharmacogenetics is important for the identification of new drug targets, reducing overall cost of treatment, gaining a better understanding of the mechanisms of action of drug treatments, prevention of adverse drug reactions and improving efficacy of medicine (Table 5).

Table 5 Importance of pharmacogenetics

Is the knowledge of pharmacogenetics likely to decrease the number of ADRs?

\begin{tabular}{|l|l|l|l|l|}
\hline & $\begin{array}{l}\text { Not Likely } \\
\mathbf{n}(\mathbf{\%})\end{array}$ & $\begin{array}{l}\text { Unsure } \\
\mathbf{n}(\mathbf{\%})\end{array}$ & $\begin{array}{l}\text { Likely } \\
\mathbf{n}(\mathbf{\%})\end{array}$ & $\begin{array}{l}\text { Very Likely } \\
\mathbf{n}(\mathbf{\%})\end{array}$ \\
\hline Medical doctor & $1(2.4)$ & $9(21.4)$ & $19(45.2)$ & $13(31.0)$ \\
\hline Pharmacist & $0(0)$ & $10(34.5)$ & $10(34.5)$ & $9(31.0)$ \\
\hline Nurse & $0(0)$ & $10(52.6)$ & $8(42.1)$ & $1(5.3)$ \\
\hline $\begin{array}{l}\text { Is the knowledge of pharmacogenetics likely to decrease the cost of develop- } \\
\text { ing drugs? }\end{array}$ \\
\hline Medical doctor & $7(16.7)$ & $17(40.5)$ & $13(31.0)$ & $5(11.9)$ \\
\hline Pharmacist & $5(17.2)$ & $13(44.8)$ & $6(20.7)$ & $5(17.2)$ \\
\hline Nurse & $4(21.1)$ & $12(63.2)$ & $3(15.8)$ & $0(0)$ \\
\hline
\end{tabular}

Table 6 provides the summary of relevant pharmacogenetics teaching-related items. Of the 32 members of faculty that responded, $7(21.9 \%)$ said pharmacogenetics was not part of the curriculum, 13 (40.6\%) did not know if pharmacogenetics was part of their institutions' curriculum. Only $12(37.5 \%)$ said it was part of their curriculum.

The authors independently verified that School of Medicine and Dentistry (UG), School of Pharmacy (UG) and School of Pharmacy (KNUST) have pharmacogenetics as part of their curriculum. School of Applied Sciences (CUC) does not have pharmacogenetics as part of their curriculum for training Pharmacist and Physician Assistants.

Table 6 Summary of relevant pharmacogenetics teaching-related items

\begin{tabular}{|l|l|l|l|}
\hline \multicolumn{1}{|c|}{ Item } & \multicolumn{1}{|c|}{$\begin{array}{c}\text { Yes } \\
\mathbf{n}(\mathbf{\%})\end{array}$} & $\begin{array}{c}\text { No } \\
\mathbf{n}(\mathbf{\%})\end{array}$ & \multicolumn{1}{|c|}{$\begin{array}{c}\text { Unaware } \\
\mathbf{n}(\mathbf{\%})\end{array}$} \\
\hline Does syllabus contain genetic information? & $19(59.4)$ & $7(21.9)$ & $6(18.8)$ \\
\hline $\begin{array}{l}\text { Does syllabus contain pharmacogenetics infor- } \\
\text { mation? }\end{array}$ & $12(37.5)$ & $7(21.9)$ & $13(40.6)$ \\
\hline $\begin{array}{l}\text { Should students be equipped with pharmaco- } \\
\text { genetics information? }\end{array}$ & $31(96.9)$ & $1(3.1)$ & $0(0)$ \\
\hline $\begin{array}{l}\text { Would you like to know more about pharmaco- } \\
\text { genetics? }\end{array}$ & $31(96.9)$ & $1(3.1)$ & $0(0)$ \\
\hline
\end{tabular}


All faculty members agreed that students should be equipped with knowledge of pharmacogenetics. Majority of the Faculty members said dissemination of knowledge of pharmacogenetics can be done through lectures and a few said through seminars. Twenty seven $(84.4 \%)$ respondents taught including pharmacogenetics in the curriculum was a better mode of equipping students with that knowledge as compared to seminars $(2,6.3 \%)$. Three faculty members did not response to this question. Twelve $(38 \%)$ of faculty members taught that less than 4 hours of pharmacogenetics education was enough to equip the students while 10 $(31.3 \%)$ taught 4 hours to 8 hours was adequate, 5 $(15.6 \%)$ taught it should be more than 8 hours and 5 $(15.6 \%)$ faculty did not give a response to this question. Majority of faculty members $(96.9 \%)$ said they would be interested in gaining more knowledge on pharmacogenetics.

\section{DISCUSSION}

Pharmacogenetics has delivered an impressive amount of information in the past 50 years; however, it has suffered from lack of integration into clinical practice. Over the past decade, pharmacogenetics has evolved into an essential tool to ensure optimal medication use for a growing number of medications and disease states. It has become important that present day health professionals (Doctors, Pharmacist, Physician Assistants and Nurses) are equipped to use pharmacogenetics information to appropriately individualize medication therapy for patients now and in the near future. ${ }^{17}$

Pharmacogenetics training in health professional institutions, however, appears to be lagging behind despite the rapid advances in research. Insufficient education of health professionals and the lack of adequate patient education have been observed as major barriers to pharmacogenetics being integrated into clinical practice. $^{15}$

This descriptive survey assessed knowledge of pharmacogenetics among health professionals and faculty members of health training institutions. The survey showed that majority of the professionals interviewed have heard about pharmacogenetics and view it as clinically relevant to their various areas of practice. Nine $(50 \%)$ of nurses however, do not think pharmacogenetics was relevant to their profession and two of these nurses do not think pharmacogenetics should be part of diagnosis and treatment.

Many of the professionals have gained their knowledge of pharmacogenetics mainly from their colleagues and the internet. It appears the pharmacogenetics information gained by these professionals were from self- directed learning which is beneficial but may result in contrasting levels of knowledge of pharmacogenetics and may lead to unequal standards of practice among these professionals. It was however encouraging to note that health professionals between the age range of 25 years to 29 years with the least years of practice experience, seemed to form the majority of the responding professionals who have heard of pharmacogenetics.

In 2004, International Society of Pharmacogenomics (ISP) meeting in Greece focused on incorporation of pharmacogenomics into the medical schools core curricula. The participants and members of the ISP Pharmacogenomics Education Forum agreed on 'Recommendations and Call for Action' to Deans of Education at Medical, Pharmaceutical, and Health Schools globally. The call was on Deans of Education to incorporate pharmacogenomics in the core teaching curricula of pharmacology without further delay. ${ }^{14}$

The National Coalition for Health Professional Education in Genetics (NCHPEG) in the USA has also made recommendations on "Core Competencies in Genetics Essential for All Health-Care Professionals"." In 2006, the American Nurses Association (ANA) established genetic competencies for nurses and recommended its use in nursing education ${ }^{10}$ and in 2007, the American Council on Pharmacy Accreditation set Pharmacogenetics as a required component of the pharmacy curriculum. ${ }^{9}$

Schools of Medicine and Pharmacy in the developed world are working to address the educational needs of their students to ensure that they are adequately prepared for pharmacogenetics challenges. Most schools of pharmacy now include pharmacogenetics content in their curriculum. ${ }^{16}$ Most US and Canadian medical schools have begun to incorporate pharmacogenetics material into their curriculum although the extent of instruction is less in Canada than it is in US pharmacy schools. $^{18}$

There are very few reports of pharmacogenetics teaching around the world reported in literature. ${ }^{13,15,16}$ These reports are almost absent from institutions in low and middle-income countries. There is an existing gap between research and practice, efforts should be made to narrow this gap. It was observed during this study that some Schools of Medicine and Pharmacy in Ghana have introduced the teaching of pharmacogenetics as part of their pharmacology curriculum. The schools without pharmacogenetics as part of their curriculum should be encouraged to initiate it into the education of their healthcare professionals. 
A recent study on perceptions of healthcare professionals towards pharmacogenetics in Nigeria concluded that Pharmacist and Pharmacologists were aware of the benefits of Pharmacogenetics. However, many cited hurdles that needed to be overcome for pharmacogenetics to become routine part of patient care. ${ }^{19}$ This study also showed that Healthcare professionals were aware of the significance of pharmacogenetics in prevention and management of adverse drug reactions. However, majority were unsure of its potential benefits to drug discovery and its role in the reduction of cost of healthcare. Clinical application of evidence-based pharmacogenetics information has the potential to help healthcare professionals provide safe and effective medication management to patients. However, there is a gap between the advances of pharmacogenetics discovery and the health professionals' knowledge regarding pharmacogenetics testing and therapeutic uses.

Teaching current health professionals in schools and continuously updating the knowledge of pharmacogenetics of those already in practice should not be postponed until a new paradigm arrives. Healthcare professional bodies should therefore endeavor to educate their members on pharmacogenetics through continuous professional development programmes so as to prepare them for the future. Such measures would assist in the development of competency standards for the health professionals for the future incorporation of pharmacogenetics into the healthcare system.

Many of the healthcare professionals interviewed were of the opinion that including pharmacogenetics into the curriculum of undergraduate students in health training institutions would provide an opportunity for these students to acquire knowledge and gain a better understanding of this field before passing out of school. General consensus among clinical pharmacology educators was that pharmacogenetics should be included in current medical school training. Based on the ISP recommendations for undergraduate medical teaching of pharmacogenetics, most British medical schools now teach pharmacogenetics for 1-2 hours. ${ }^{15}$ Data from this survey suggests 4 hours to 8 hours of teaching pharmacogenetics be incorporated into the curricula of medical and pharmacy schools in Ghana. This can be done at the stage when the students are already familiar with basic principles of pharmacokinetics, pharmacodynamics and have completed their basic training in human genetics. Pharmacogenetics can also be taught as an elective semester-long graduate programme for postgraduate students. Health training institutions need to assist their faculty members to develop the requisite skill and knowledge to present pharmacogenetics information to students.
Collaborative programmes with other educational institutions that have the expertise in the area can be the starting point.

Health training institutions may start by introducing their students to core areas such as definition of pharmacogenetics, aims of pharmacogenetics, clinical examples of pharmacogenetics, potential advantages and disadvantages of pharmacogenetics and the future of pharmacogenetics. The mode of instruction may be lectures for undergraduate students, seminars and caseled for post graduate and practicing professionals.

Clinical Pharmacogenetics Implementation Consortium (CPIC) formed in 2009 with an ultimate goal of guiding clinicians to make patient care decisions for specific drugs when genetic results are available. CPIC has been providing a comprehensive review of the existing literature on targeted pharmacogenetic examples and providing guidelines authored by experts in the field on the clinical use of pharmacogenetic information. CPIC has focused on available pharmacogenetic data and how the clinician can use this genetic information to guide drug therapy. More than fifteen CPIC guidelines have been published and these include TPMT and thiopurines, CYP2C19 and clopidogrel, VKORC1/CYP2C9 and warfarin, $C Y P 2 D 6$ and codeine, $H L A-B$ and abacavir, $S L C O 1 B 1$ and simvastatin, $H L A-B$ and allopurinol, and $C Y P 2 D 6 / C Y P 2 C 19$ and tricyclic antidepressants $^{20}$ which can be used as teaching matarial in schools and for CPD seminars.

Introducing pharmacogenetics teaching will have an effect on other areas of the school curriculum; however, there is the need to find that balance to give our healthcare professionals the opportunity to compete on the world stage. A number of studies have been done in Ghana over the years in the area of pharmacogenetics. ${ }^{2}$ It is about time to start introducing students to pharmacogenetics in all health training institutions in Ghana.

\section{CONCLUSION}

These findings provide baseline information on the knowledge of pharmacogenetics among practicing health professionals and faculty members of the Health training institutions. Some of these professionals are aware of the emerging field of pharmacogenetics and taught it was relevant to their individual professions especially in the areas of diagnosis and treatment. A few health training institutions have introduced pharmacogenetics into their curriculum but many are yet to do so. There is the need for continuous professional development education in pharmacogenetics to even out the knowledge base of all healthcare professionals. 


\section{Study limitations}

One limitation of our study is that practicing Healthcare professionals were selected from hospitals and private clinics in only Accra/Tema metropolitan area of Greater Accra region of Ghana. This may not be representative of all healthcare professionals in Ghana. Faculty members of the newly establish health training institutions were not part of this study. In spite of these limitations, this study provides the first glimpse of knowledge pharmacogenetics in Ghana.

\section{ACKNOWLEDGEMENT}

The authors would like to express their appreciation to Mr Edmund Nartey of School of Medicine and Dentistry for statistical analysis of the data.

\section{REFERENCES}

1. Webster A, Martin P, Lewis G, Smart A. Integrating pharmacogenetics into society: in search of a model. Nat Rev Genet 2004;5(9):663-9.

2. Kudzi W, Adjei GO, Ofori-Adjei D, Dodoo AN. Pharmacogenetics in Ghana: reviewing the evidence. Ghana Med J 2011;45(2):73-80.

3. Pirmohamed M. Pharmacogenetics and pharmacogenomics. $\mathrm{Br} J$ Clin Pharmacol 2001;52(4):345-7.

4. Giacomini KM, Brett CM, Altman RB, et al. The pharmacogenetics research network: from SNP discovery to clinical drug response. Clin Pharmacol Ther 2007;81(3):328-45.

5. Lesko LJ. Personalized medicine: elusive dream or imminent reality? Clin Pharmacol Ther 2007;81(6):807-16.

6. Pang GS, Wang J, Wang Z, Lee CG. Predicting potentially functional SNPs in drug-response genes. Pharmacogenomics 2009;10(4):639-53.

7. Frueh FW, Amur S, Mummaneni P, et al. Pharmacogenomic biomarker information in drug labels approved by the United States food and drug administration: prevalence of related drug use. Pharmacotherapy 2008;28(8):992-8.

8. Marsh S. Pharmacogenetics: global clinical markers. Pharmacogenomics 2008;9(4):371-3.
9. Johnson JA BJ, Evans WE, et al. Pharmacogenetics. A scientific revolution in pharmaceutical sciences and pharmacy practice. Report of the 2001 2002 Academic Affairs Committee. . Am J Pharm Educ 2002;66:12S-17S.

10. Jenkins J, Calzone KA. Establishing the essential nursing competencies for genetics and genomics. $J$ Nurs Scholarsh 2007;39(1):10-6.

11. Recommendations of core competencies in genetics essential for all health professionals. Genet Med 2001;3(2):155-9.

12. Moridani M. The Significance of Pharmacogenomics in Pharmacy Education and Practice American Journal of Pharmaceutical Education 2005;69 (2) Article 37.

13. Latif DA. Pharmacogenetics and pharmacogenomics instruction in schools of pharmacy in the USA: is it adequate? Pharmacogenomics 2005;6(4):317-9.

14. Gurwitz D, Lunshof JE, Dedoussis G, et al. Pharmacogenomics education: International Society of Pharmacogenomics recommendations for medical, pharmaceutical, and health schools deans of education. Pharmacogenomics J 2005;5(4):221-5.

15. Higgs JE, Andrews J, Gurwitz D, Payne K, Newman W. Pharmacogenetics education in British medical schools. Genomic Med 2008;2(3-4):101-5.

16. Murphy JE, Green JS, Adams LA, Squire RB, Kuo GM, McKay A. Pharmacogenomics in the curricula of colleges and schools of pharmacy in the United States. Am J Pharm Educ 2010;74(1):7.

17. Roederer MW, Sanchez-Giron F, Kalideen K, Kudzi W, McLeod HL, Zhang W. Pharmacogenetics and rational drug use around the world. Pharmacogenomics 2011;12(6):897-905.

18. Green JS, O'Brien TJ, Chiappinelli VA, Harralson AF. Pharmacogenomics instruction in US and Canadian medical schools: implications for personalized medicine. Pharmacogenomics 2010;11(9): 1331-40.

19. Madadi P. EE, Babatunde EO. Perceptions of health care professionals towards pharmacogenetics in Nigeria: Preliminary Results. West African Journal of Pharmacy 2011;1:97 - 101. 